\title{
Lights on for HIF-1 $\alpha$ : Genetically Enhanced Mouse Cardiomyocytes for Heart Tissue Imaging
}

\author{
Amke R. Hesse ${ }^{a} \quad$ Elif Levent ${ }^{b, c} \quad$ Anke Zieseniss ${ }^{a, c}$ Malte Tiburcy ${ }^{b, c}$ \\ Wolfram H. Zimmermann ${ }^{b, c}$ Dörthe M. Katschinskia, ${ }^{a}$, \\ anstitute of Cardiovascular Physiology and 'Institute of Pharmacology, University Medical Center, \\ Georg-August-University Göttingen, 'DZHK (German Center for Cardiovascular Research), partner site \\ Göttingen, Göttingen, Germany
}

\section{Key Words}

Hypoxia $•$ Oxygenation $•$ Engineered heart muscle $\cdot$ HIF-1 $\alpha$

\begin{abstract}
Background/Aims: The hypoxia inducible factor-1 (HIF-1) is a suitable marker for tissue oxygenation. We intended to develop cardiomyocytes (CMs) expressing the oxygendependent degradation domain of HIF-1 $\alpha$ fused to the firefly luciferase (ODD-Luc) followed by proof-of-concept for its applicability in the assessment of heart muscle oxygenation. Methods and Results: We first generated embryonic stem cell (ESC) lines (ODD-Luc ESCs) from a Tg ROSA26 ODD-Luc/+ mouse. Subsequent CMs selection was facilitated by stable integration of an antibiotic resistance expressed under the control of the $\alpha \mathrm{MHC}$ promoter. ODD-Luc ESCs showed a strong Luc-signal within $1 \mathrm{~h}$ of hypoxia (1\% oxygen), which coincided with endogenous HIF- $1 \alpha$. Engineered heart muscle (EHM) constructed with ODD-Luc CMs confirmed the utility of the model to sense hypoxia, and monitor reoxygenation also in a multicellular heart muscle model. Pharmacologically induced inotropy/chronotropy under isoprenaline resulted in enhanced Luc-signal suggesting enhanced oxygen consumption, leading to notable myocardial hypoxia. Conclusions: ODD-Luc-CMs can be used to monitor dynamic changes of cardiomyocyte oxygenation in living heart muscle samples. We provide proof-of-concept for pharmacologically induced myocardial interventions and envision applications of the developed model in drug screens and fundamental studies of ischemia/ reperfusion injury.
\end{abstract}

A.R. Hesse and E. Levent contributed equally. 


\section{Cellular Physiology and Biochemistry}

Cell Physiol Biochem 2014;34:455-462

DOI: 10.1159/000363014

Publisned onilne: July 30, 2014

(C) 2014 S. Karger AG, Basel

www.karger.com/cpb

456

Hesse et al.: Hypoxia Imaging in Engineered Heart Tissue

\section{Introduction}

Means to visualize hypoxia in the heart are limited. Thus, a screening platform for analyzing cardiac oxygenation is highly wanted to monitor the effects of physiological stimuli or therapeutic agents. The hypoxia inducible factor-1 (HIF-1) is the master regulator of the hypoxia-inducible gene expression in all tissues, including the heart. HIF comprises an oxygen-dependently regulated $\alpha$-subunit and a constitutively expressed $\beta$-subunit. The molecular basis for the hypoxia-induced stability of HIF-1 $\alpha$ is an oxygen-dependent hydroxylation by the prolyl-4-hydroxylase-domain (PHD) enzymes [1,2]. Any decrease in the availability of oxygen is mirrored by the hydroxylation activity and thus the stability of HIF- $1 \alpha$. Following prolyl-4-hydroxylation of the critical prolyl residues, von Hippel-Lindau ubiquitin ligase targets HIF-1 $\alpha$ for rapid degradation [3]. Therefore, the respective protein domain of HIF has been named the oxygen dependent degradation domain (ODD). Recently, a Tg ROSA26 ODD-Luc/+ mouse line for the in vivo monitoring of HIF-1 $\alpha$ stability was reported [4]. In these mice, the reporter fusion protein ODD-(aa530-652)-firefly luciferase (Luc) is constitutively expressed. This results in an oxygen-dependent Luc signal in the intact mouse and the possibility for non-invasive measurements of tissue hypoxia. Based on the constitutive active CMV promoter, it is however not possible to analyze specific tissues or cell types separately. Moreover, the major drawback of luminescence in vivo imaging systems is its limited depth penetration under whole animal imaging conditions [5]. Cardiac tissue engineering has made notable progress in recent years and provided us with heart muscle model tissues, such as engineered heart muscle (EHM), for modelling heart development, homeostasis, and disease like ischemia/reperfusion (I/R) [6]. Here, we demonstrate the establishment of ODD-Luc hypoxia reporter cardiomyocytes and provide proof-of-concept for their utility in hypoxia imaging in EHM.

\section{Materials and Methods}

Tg ROSA26 ODD-Luc/+ mice

TG ROSA26 ODD-Luc/+ mice were originally generated by Safran et al [4] and obtained from Jackson Laboratory.

\section{LAD ligation and bioluminescence imaging of the heart}

All protocols regarding animal experimentation were conducted according to the German animal protection laws and approved by the responsible governmental authority (Niedersächsisches Landesamt für Verbraucherschutz und Lebensmittelsicherheit; animal experimentation number 33.9-42502-04-10/0069). In brief, mice were anaesthetized (1.5\% isofluran). The trachea was surgically exposed, and tracheal intubation was performed. A blunt intubation cannula (Intubation Cannula, Stainless Steel - with Y-adapter, $1.2 \mathrm{~mm}$ OD, $30 \mathrm{~mm}$ length, Hugo Sachs Elektronik, Harvard Apparatus GmbH) was inserted into the trachea. Correct tube placement was confirmed by direct visualization of the cannula within the previously exposed trachea. The tracheal tube was connected to a mechanical ventilator (MiniVent, Hugo Sachs Elektronik Harvard Apparatus $\mathrm{GmbH}$ ) and the animals were ventilated by using a volume-controlled ventilation mode (stroke volume $150 \mu \mathrm{l}, 150$ strokes/min). After exposing the heart, the pericardium was removed, and a 9-0 polyamide suture with an U-shaped needle was passed under the left anterior descending artery (LAD). The suture was tied to occlude the artery. Sham operated animals were treated like the LAD-ligated animals regarding anaesthesia, opening of the thorax, placing the suture around the LAD, but omitting its ligation. The chest was closed and the mouse recovered. Four hours after LAD ligation the mice were given a single i.p. injection luciferin (130 mg/kg body weight), $15 \mathrm{~min}$ later the mice were anaesthetized and sacrificed, and the hearts were excised. The hearts were cut in three slices, an apical, middle, and a basal section. The slices were rinsed with PBS and transferred into a luciferin solution $(300 \mu \mathrm{g} / \mathrm{ml}$ in PBS). The luminescence of the heart slices was measured in a light-tight chamber with a luminescence image analyser (LAS-3000, Fuji Film Europe, Düsseldorf, Germany). The luminescence signals were further analysed using the image processing programme Image J. The sum of the luminescence values of the three slices obtained from one 


\section{Cellular Physiology and Biochemistry}

Cell Physiol Biochem 2014;34:455-462

DOI: $10.1159 / 000363014$

Published oniıne: July 30, 2014

(C) 2014 S. Karger AG, Basel

www.karger.com/cpb

Hesse et al.: Hypoxia Imaging in Engineered Heart Tissue

heart was considered when comparing the Luc activity after myocardial infarction compared to shamoperated animals.

\section{Establishment ODD-Luc ESCs}

Tg ROSA26 ODD-Luc/+ mice were mated. After vaginal plug control, two-cell stage embryos were harvested by flushing the excised oviducts with M2 medium. After cumulus cell removal with hyaluronidase (1 $\mathrm{mg} / \mathrm{ml}, 10 \mathrm{~min}$ at room temperature), zygotes were cultured to blastocyst stage in mineral oil covered CZB-medium (mmol/l: NaCl 82.7, KCl 4.68, CaCl2 1.71, KH2PO4 1.17, MgSO4 1.18, D-glucose 5.6, Na-lactate 30.1, EDTA 0.1, NaHCO3 25, Na-pyruvate 0.62, glutamine 1; supplemented with $5 \mathrm{mg} / \mathrm{ml}$ bovine serum albumin, $100 \mathrm{U} / \mathrm{ml}$ penicillin, and $100 \mu \mathrm{g} / \mathrm{ml}$ streptomycin). After 3.5-4.5 days in suspension culture, blastocysts were transferred onto mitomycin C $(10 \mu \mathrm{g} / \mathrm{ml})$ inactivated mouse embryonic fibroblasts (MEF) in knock-out medium (Gibco) with 20\% serum replacement (Gibco), 1,000 U/ml leukaemia inhibitory factor (LIF; Chemicon), $2 \mathrm{mmol} / \mathrm{L}$ glutamine, $1 \mathrm{x}$ non-essential amino acids, $0.1 \mathrm{mmol} / \mathrm{L} \beta$-mercaptoethanol, 50 $\mathrm{U} / \mathrm{ml}$ penicillin, and $50 \mu \mathrm{g} / \mathrm{ml}$ streptomycin. Inner cell mass outgrowths were micro-dissected after 4-5 days, enzymatically dispersed (0.25\% trypsin/EDTA), and plated on MEFs in DMEM (4.5 g/l glucose, no pyruvate, $25 \mathrm{mmol} / \mathrm{L}$ HEPES) with $20 \%$ fetal calf serum, 1 streptomycin). Cells were passaged every 4872 hours. ODD-Luc ESC colonies were identified by their unique morphological appearance and growth characteristics.

\section{Establishment ODD-Luc x $\alpha M H C$-neoR ESCs}

ODD-Luc ESC were electroporated with a DNA fragment encoding for a neomycin resistance (neoR) under the control of the cardiomyocyte specific alpha-myosin heavy chain ( $\alpha \mathrm{MHC}$ aka MYH6) promoter and a hygromycin resistance (hygroR) under the ubiquitously active phosphoglycerate kinase (PGK) promoter and selected under hygromycin (kindly provided by L. Field, Indianapolis) [7].

Differentiation of ODD-Luc cardiomyocytes (CMs)

Cardiac differentiation was performed in $100 \mathrm{ml}$ spinner flask cultures $\left(0.1 \times 10^{6}\right.$ cells $/ \mathrm{ml}$ seeding density) for 11+7 days at $60 \mathrm{rpm}$ in differentiation medium (DMEM Iscove Basal Medium with 20\% fetal calf serum, $1 \mathrm{x}$ non-essential amino acids, $2 \mathrm{mmol} / \mathrm{L}$ L-glutamine, $100 \mathrm{U} / \mathrm{ml}$ penicilin, $100 \mu \mathrm{g} / \mathrm{ml}$ streptomycin, $0.1 \mathrm{mmol} / \mathrm{L} \beta$-mercaptoethanol, $0.3 \mathrm{mmol} / \mathrm{L}$ ascorbic acid). For cardiomyocyte enrichment, G418 (400 $\mu \mathrm{g} /$ $\mathrm{ml}$; Invitrogen) was added from culture day 11 for 7 days.

\section{EHM construction}

EHMs were constructed from the purified cardiomyocytes and MEF (70:30) as described previously [8]. Briefly, cells $\left(1.5 \times 10^{6} / \mathrm{EHM}\right)$ were mixed with $\mathrm{pH}$ neutralized rat tail collagen type I (0.4 mg/EHM) supplemented with 2xDMEM containing 40\% fetal calf serum, $200 \mathrm{U} / \mathrm{ml}$ penicillin, $200 \mu \mathrm{g} / \mathrm{ml}$ streptomycin (cell/collagen mixture:DMEM - 1:1 v/v). For construction of a single EHM $450 \mu \mathrm{l}$ of the reconstitution mixture was pipetted into circular casting molds, left to condense for $1 \mathrm{~h}$, and subsequently immersed in Iscove's medium with $20 \%$ fetal calf serum, $1 \mathrm{x}$ non-essential amino acids, $2 \mathrm{mmol} / \mathrm{L} \mathrm{L}$-glutamine, $100 \mathrm{U} / \mathrm{ml}$ penicillin, $100 \mu \mathrm{g} / \mathrm{ml}$ streptomycin (all Invitrogen), $0.1 \mathrm{mmol} / \mathrm{L} \beta$-mercaptoethanol, $0.3 \mathrm{mmol} / \mathrm{L}$ ascorbic acid (Sigma-Aldrich) under $5 \% \mathrm{CO}_{2}$ and $21 \% \mathrm{O}_{2}$ at $37^{\circ} \mathrm{C}$. After 3 days, consolidated EHMs were transferred onto custom-made static stretch devices for additional 7 culture days.

\section{Imaging bioluminescence}

EHMs were removed from the stretchers, transferred in luciferin (Caliper) solution (1 $\mathrm{mg} / \mathrm{ml}$ in PBS) and incubated for $1 \mathrm{~min}$. The EHMs were subsequently placed on a $10 \mathrm{~cm}$ cell culture dish, covered with a glass slide and imaged in a light-tight chamber with a luminescence image analyzer (LAS-3000).

Hypoxia

For incubation in hypoxia the Invivo 400 workstation (Ruskinn, UK) was used.

Western blots

ODD-Luc CMs were lysed in passive lysis buffer (Promega) containing protease inhibitors (Roche). Protein concentrations were quantified (Bio-Rad, DC Protein Assay). For immunoblot analysis protein 


\section{Cellular Physiology and Biochemistry}

Cell Physiol Biochem 2014;34:455-462

DOI: $10.1159 / 000363014$

Published online: july 30, 2014

(C) 2014 S. Karger AG, Basel

www.karger.com/cpb

458

Hesse et al.: Hypoxia Imaging in Engineered Heart Tissue

samples were resolved by SDS/PAGE and transferred onto nitrocellulose membranes (Amersham Biosciences) by semi-dry blotting (PeqLab). Primary antibodies used were: anti-PHD2 (Novus, NB1002219), anti-HIF-1 $\alpha$ (Novus, NB100-479), anti-firefly luciferase (Abcam, ab64564) and anti-tubulin (Abcam, ab6046). The polyclonal anti-HIF-1 $\alpha$ antibody detects the HIF-1 $\alpha$ protein as well as the ODD-Luc fusion protein. The anti-firefly antibody detects the ODD-Luc fusion protein and was used to confirm that the lower band detected with the anti-HIF-1 $\alpha$ antibody resembles the fusion protein.

For detection of immunocomplexes horseradish peroxidase-conjugated secondary goat anti-rabbit or goat anti-mouse antibodies (Santa Cruz Biotechnology) were used and membranes were incubated with $100 \mathrm{mM}$ Tris- $\mathrm{HCl}$ ( $\mathrm{pH}$ 8.5), $2.65 \mathrm{mM} \mathrm{H}_{2} \mathrm{O}_{2}, 0.45 \mathrm{mM}$ luminol, and $0.625 \mathrm{mM}$ coumaric acid for $1 \mathrm{~min}$ (for the detection of HIF-1 $\alpha$, PHD2, and tubulin) or with Immobilon ${ }^{\mathrm{TM}}$ Western chemiluminescence HRP substrate (Millipore, for the detection of firefly luciferase). Chemiluminescence signals were detected with the luminescence image analyser LAS-3000.

\section{Statistics}

All bars represent mean \pm SEM. Comparison of two groups was done by student`s t-test. Multiple groups were analyzed by ANOVA followed by Bonferroni post hoc test. * $\mathrm{p}<0.05$.

\section{Results}

Myocardial infarction in ODD-Luc mice

Tg ROSA26 ODD-Luc/+ mice have been used to study the response to hypoxia [4]. However, the signals obtained in the heart were relatively low. This reflects at least in part an insufficient reconstruction of the distribution of bioluminescence in the thorax from data measured on the animal surface and reflects the drawback of bioluminescence in vivo imaging for the heart. To scrutinize whether the hearts of Tg ROSA26 ODD-Luc/+ mice respond to an acute hypoxic event, we performed myocardial infarction and analyzed the isolated hearts 4 hours after permanent LAD occlusion (Fig. 1A and B). Compared to sham treated animals, the cardiac slices of the infarcted animals demonstrated significant higher Luc counts, demonstrating that cardiac tissue responded to the ischemic insult. This experimental procedure represents an end-point experiment and the need of sacrificing the animals for imaging prevents analysis of dynamic changes over time. Moreover, cardiac tissue comprises of cardiomyocytes and a considerably large non-cardiomyocyte cell fraction ( $70 \%$ in total cell number and $30 \%$ in total heart mass) $[9,10]$. The specific response of cardiomyocytes cannot be investigated in the Tg ROSA26 ODD-Luc/+ mice because ODD-Luc is controlled by the constitutively active CMV-promoter. Therefore, we sought to address these limitations by establishing a heart muscle model system with ODD-Luc cardiomyocytes and genetically naïve non-myocytes, which can be used as a screening platform.

\section{Generation of hypoxia reporter cardiomyocytes (ODD-Luc-CMs)}

ESCs were isolated from blastocyst stage Tg ROSA26 ODD-Luc/+ mice. Exposure of the ODD-Luc ESCs to $1 \% \mathrm{O}_{2}$ resulted in a significant increase in Luc-signal (Fig. 2A and B). Non-specific luminescence was negligible (A3-ESC $\alpha$ MHC-neoR line served as control). We subsequently generated a double transgenic cell line by stable integration of a neomycin resistance (neoR) gene under the control of the cardiomyocyte-restricted $\alpha \mathrm{MHC}$-promoter element (refer to methods). Selection under G418 resulted in 90\% cardiomyocyte purity as assessed by staining for $\alpha$-sarcomeric actinin staining. Exposure of the ODD-Luc-CM to $1 \% \mathrm{O}_{2}$ for 1-72 hours, demonstrated a significant increase of Luc-signal over time (Fig. 2C). Luminescence intensity peaked 24 hours after the start of hypoxia and subsequently decreased again. A similar kinetic profile was observed by analyzing the ODD-Luc fusion protein by Western blotting (Fig. 2D), confirming that the bioluminescence correlated well with the abundance of the oxygen-dependently regulated ODD-Luc fusion protein. Importantly, the endogenous HIF-1 $\alpha$ protein showed a similar pattern after induction of hypoxia with a blunted signal after 48-72 hours. As part of the hypoxic transcriptional 
Fig. 1. ODD-Luc mouse hearts respond to in vivo hypoxia with enhanced Luc-signals. (A) ODD-Luc mice underwent either sham surgery or myocardial infarction (MI, $\mathrm{n}$ $=6$ mice in each treatment group) Hearts were excised, sectioned and analyzed for Luc-signal 4 hours after the surgical interventions. (B) Colorcoded image of sham and MI hearts (blue is low, red is high Luc-signal).

\section{A}

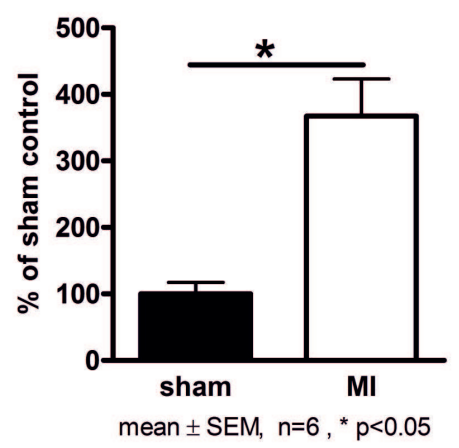

B

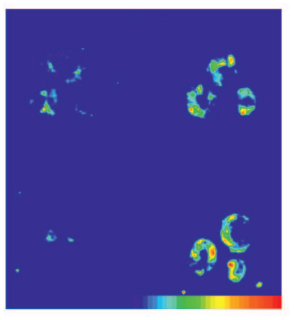

sham
A

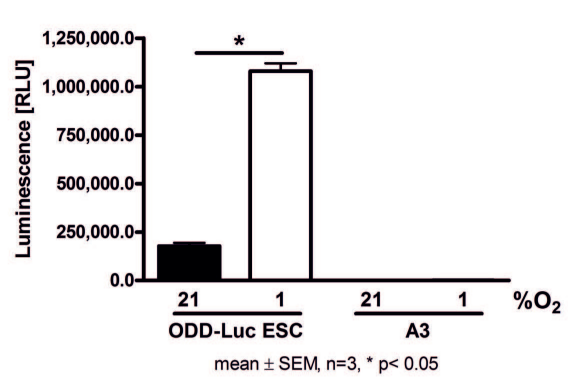

B

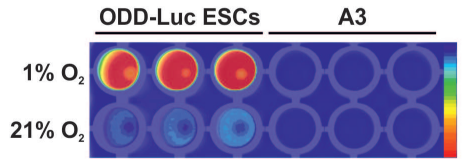

C

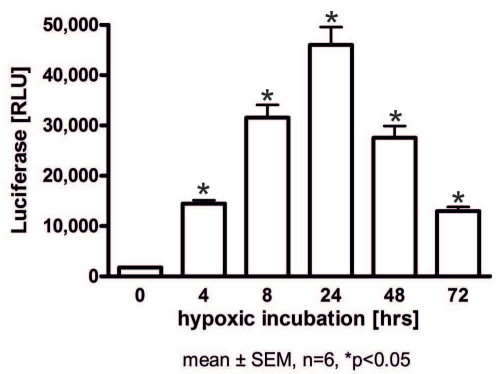

D

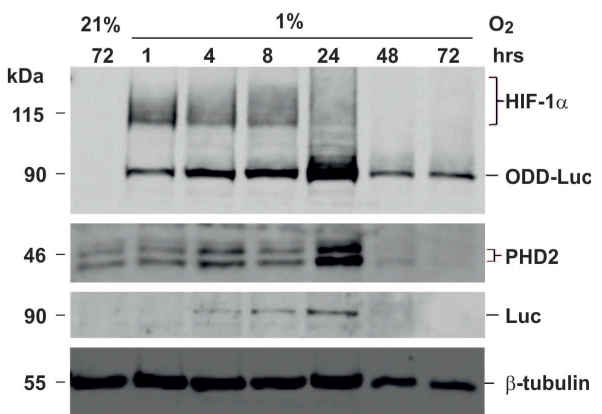

Fig. 2. Characterization of an ODD-Luc ESC line. (A) ODD-Luc ESCs and control A3-ESCs ( $\alpha$ MHC-neoR) were exposed to $21 \%$ or $1 \% \mathrm{O}_{2}$ for 4 hours followed by Luc-signal analysis; n.d., not detectable, $\mathrm{n}=3$ samples for each condition. (B) Color-coded image of the ODD-Luc ESC and control A3-ESC line cultured in $1 \% \mathrm{O}_{2}$ or $21 \% \mathrm{O}_{2}$; blue is low, red is high Luc-signal. (C) Selected ODD-Luc-CMs ( $\sim 90 \%$ purity) were exposed to $21 \%$ or $1 \% \mathrm{O}_{2}$ as indicated followed by Luc-signal analysis, $\mathrm{n}=6$ samples for each time point. (D) Protein extracts of ODD-Luc-CMs after hypoxic exposure subjected to Western blot analysis for HIF-1 $\alpha$, firefly luciferase (Luc), PHD2 protein and $\beta$-tubulin.

response HIF activates among others PHD2 transcription. This compensates partly for the decreased oxygen concentration and thus allows to determinate the acute hypoxic response [11]. Accordingly, PHD2 protein was elevated after 24 hours of hypoxia and markedly decreased after 48 hours, being in line with the loss of HIF-1 $\alpha$ as well as the reduction of Luc-signal to baseline levels. 
Fig. 3. Modelling of ischemia-reperfusion injury in ODD-Luc EHM. (A and B) ODD-Luc EHMs were exposed to $1 \%$ or $21 \%$ $\mathrm{O}_{2}$ as indicated. Subsequently, EHMs were analyzed for Luc-signal intensity compared to a respective normoxic $(21 \%$ $\mathrm{O}_{2}$ ) EHM. $\mathrm{n}=3$ EHMs for each time point. Panels below the graphs display the color-coded signal recorded from ODD-Luc EHM (blue is low, red is high Luc-signal).

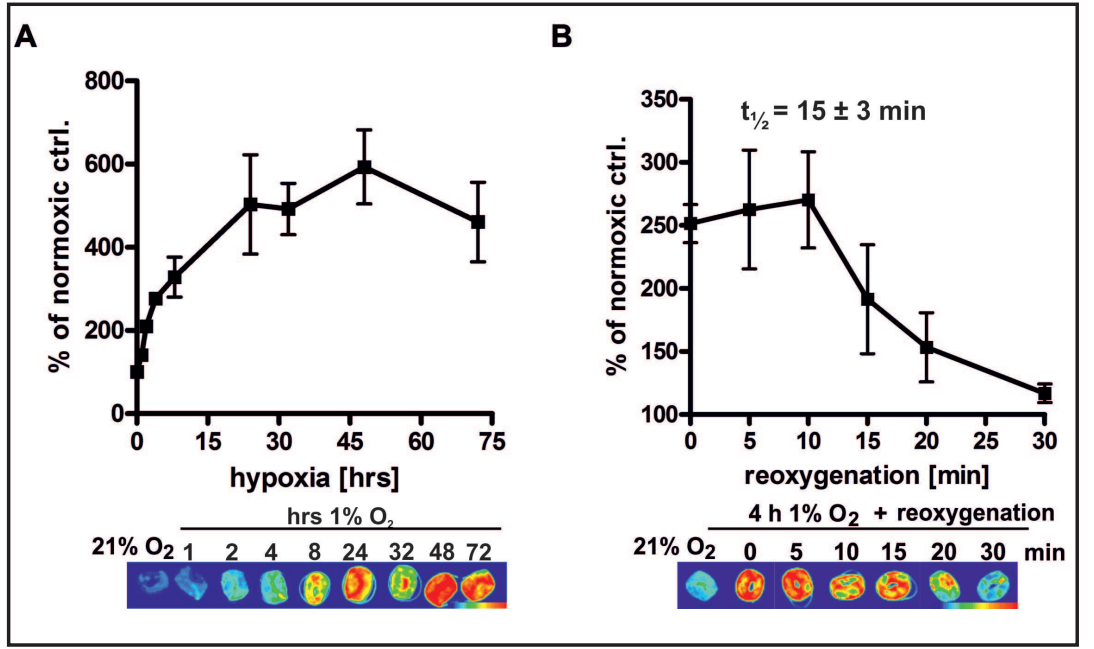

Fig. 4. Modelling of pharmacologically induced hypoxia in ODD-Luc EHM. (A) ODD-Luc EHMs were stimulated with $1 \mu \mathrm{mol} / \mathrm{L}$ isoprenaline at $21 \% \mathrm{O}_{2}$ for $20 \mathrm{~min}$ ( $\mathrm{n}=3$ independent EHMs in both treatment groups). Subsequently, EHMs were subjected to Lucsignal quantification. (B) Color-coded image of control ODD-Luc EHMs and the isoprenaline-stimulated EHMs (blue is low, red is high Luc-signal; note that we enhanced sensitivity and

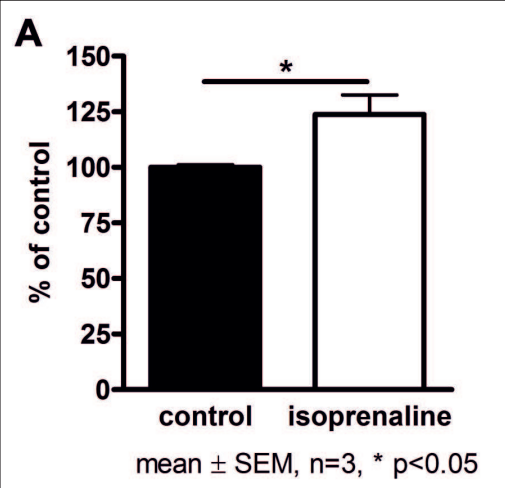

B

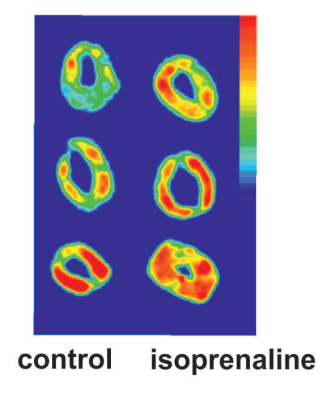

fitted the dynamic range of the Luc-signal analyzer to the anticipated signal range to pick up the anticipated small differences under inotropic/chronotropic stimulation).

Real time imaging of ODD-Luc stabilization in EHMS

ODD-Luc-CMs (70\%) and genetically naïve fibroblasts (30\%) were used to construct EHMs. ODD-Luc EHMs were exposed for 1-72 hours to $1 \% \mathrm{O}_{2}$ (Fig. 3A). Luc-signals increased with a similar kinetic as determined for the ODD-Luc-CMs. Highest signals were recorded after a hypoxic exposure of 24-48 hours in three independent experiments. Signals decreased again after 72 hours. To analyze whether the ODD-Luc signal would respond properly to tissue reoxygenation, EHMs were reexposed to $21 \%$ after 4 hours of hypoxia (1\% oxygen; Fig. 3B). 4 hours hypoxia was chosen since the Luc-signal of the EHMs was not affected by the endogenous negative feedback mechanism, leading to HIF-1 $\alpha$ destabilization under chronic hypoxia. Luc-signal decreased quickly after reoxygenation with an apparent half-life of $15 \pm$ $3 \min (n=3)$.

Pharmacologically induced hypoxia in ODD-Luc EHMs

Hypoxia can be caused by reduced oxygen supply, or, when cells are stimulated inotropically [12-14]. Isoprenaline elicits a classical positive inotropic/chronotropic effect in EHM resulting in increased oxygen consumption, but its consequences on cardiomyocyte oxygenation in the heart have to our knowledge not been assessed. For a proof-of-concept experiment we stimulated EHMs with maximally inotropically and chronotropically active isoprenaline concentrations $(1 \mu \mathrm{mol} / \mathrm{L})$ for $20 \mathrm{~min}$ (Fig. 4A and B). This resulted in a significant increase in Luc in the stimulated EHMs confirming that the hypoxia/HIF system was affected. 


\section{Cellular Physiology and Biochemistry}

Cell Physiol Biochem 2014;34:455-462

DOI: 10.1159/000363014

ublished onIIne: July 30, 2014

C) 2014 S. Karger AG, Basel

www.karger.com/cpb

461

Hesse et al.: Hypoxia Imaging in Engineered Heart Tissue

\section{Discussion}

Tools to analyze myocardial and in particular cardiomyocyte oxygenation will be instrumental to gain mechanistic insight into diseases like I/R injury and potentially also as a screening tool for drugs. Here we demonstrate that genetically modified cardiomyocytes, expressing the hypoxia-sensitive ODD-Luc, can identify myocardial oxygenation levels. Generation of EHM from ODD-Luc-CMs appears to be particularly useful given its close resemblance with bona fide heart muscle as well as the current limitations of monitoring cardiomyocyte oxygenation in vivo [15]. It is important to note that the HIF system does not rely on absolute tissue oxygenation levels but responds dynamically and linearly to changes in the oxygen availability [16]. This feature is conserved in the ODD-Luc EHMs and exemplified by the short half-time of the bioluminescence signal upon reoxygenation $(15 \pm 3 \mathrm{~min})$. The half-life is consistent with the half-life of endogenous HIF-1 $\alpha$ [17]. The PHD/HIF system resembles a biological sensing mechanism, which mirrors any decrease in the oxygen availability [18]. Furthermore, the system can adapt to a new normoxic setpoint based on the increased expression of the PHDs under hypoxia [19]. This creates a negative feedback mechanism, which determinates the acute hypoxic response and allows increasing the response to a further decrease of the oxygenation [11, 20]. ODD-Luc EHMs resemble this dynamic and flexible sensing system. It should be however mentioned that the PHD activities can be affected by other factors such as NO or reactive oxygen species besides hypoxia $[21,22]$. This would be reflected in altered ODD-Luc signals likewise. Since this response, however resembles the normal regulation of HIF and therefore the biological hypoxia signaling pathway, the ODD-Luc EHMs would reflect this physiological response.

Creating a tissue engineered model for the heart to determine the endogenous biological response towards hypoxia seems to be advantageous over determining absolute $p \mathrm{O}_{2}$ values. Most of the technical $p \mathrm{O}_{2}$ sensors, e.g. of Clark-type, consume oxygen and thus blur measurements of $p \mathrm{O}_{2}$ [23]. Targeting the oxygen sensing mechanism specifically to cardiomyocytes provides a cell type context resolution and may also be advanced to other cell types by making use of adequate genetic tools, i.e., cell type specific promoters. In this regard, it should however be mentioned that in the EHMs the cardiomyocytes are supplied by oxygen through diffusion via the culture medium only since vessels are lacking in this tissue model system. This limitation should be considered when comparing the oxygenation of the heart in situ and of the EHMs. Nevertheless, the ODD-Luc EHM model was able to detect changes in oxygen consumption. We demonstrate that inotropic/chronotropic interventions by isoprenaline do not only enhance oxygen consumption, but stabilize HIF- $1 \alpha$, which should result in the canonical activation of hypoxia response genes. This suggests activation of hypoxia associated transcription under sympathetic activation. Thus, in addition to modelling hypoxic responses of the heart, ODD-Luc EHM may be instrumental in screening for drug effects or other interventions on hypoxic transcriptome programming.

\section{Conclusions}

We have established a new genetic tool to analyze the hypoxic response of cardiac tissue. The system responds quickly and dynamically to changes in the oxygen availability and also reacts to pharmacological interventions. We anticipate that ODD-EHM may find useful applications in drug screening and fundamental studies of cardiac physiology/ pathophysiology.

\section{Acknowledgements}

We thank Andreas Schraut for generating the ODD-Luc ESC and ODD-Luc/ $\alpha$ MHC-neoR lines and Christian Dullin for technical support. This work was supported by the DZHK, the DFG (ZI708/7-1, 8-1, 10-1, SFB 1002 TP C04 and S, IRTG 1618), and the European Union (FP7-CARE-MI). 


\section{Cellular Physiology and Biochemistry}

Cell Physiol Biochem 2014;34:455-462

\begin{tabular}{l|l}
\hline DOI: $10.1159 / 000363014$ & (C) 2014 S. Karger AG, Basel
\end{tabular}

Published online: July 30, $2014 \quad$ www.karger.com/cpb

Hesse et al.: Hypoxia Imaging in Engineered Heart Tissue

\section{References}

1 Jaakkola P, Mole DR, Tian YM, Wilson MI, Gielbert J, Gaskell SJ, von Kriegsheim A, Hebestreit HF, Mukherji M, Schofield CJ, Maxwell PH, Pugh CW, Ratcliffe PJ: Targeting of HIF- $\alpha$ to the von hippel-lindau ubiquitylation complex by $\mathrm{O}_{2}$-regulated prolyl hydroxylation. Science 2001;292:468-472.

- Ivan M, Kondo K, Yang H, Kim W, Valiando J, Ohh M, Salic A, Asara JM, Lane WS, Kaelin Jr WG: Hifa targeted for vhl-mediated destruction by proline hydroxylation: Implications for $\mathrm{O}_{2}$ sensing. Science 2001;292:464468.

- 3 Min JH, Yang H, Ivan M, Gertler F, Kaelin WG Jr, Pavletich NP: Structure of an HIF-1 $\alpha$-pvhl complex: Hydroxyproline recognition in signaling. Science 2002;296:1886-1889.

4 Safran M, Kim WY, O'Connell F, Flippin L, Gunzler V, Horner JW, Depinho RA, Kaelin WG, Jr: Mouse model for noninvasive imaging of hif prolyl hydroxylase activity: Assessment of an oral agent that stimulates erythropoietin production. Proc Natl Acad Sci 2006;103:105-110.

$\checkmark 5$ Close DM, Xu T, Sayler GS, Ripp S: In vivo bioluminescent imaging (bli): Noninvasive visualization and interrogation of biological processes in living animals. Sensors 2011;11:180-206.

6 Karikkineth BC, Zimmermann WH: Myocardial tissue engineering and heart muscle repair. Curr Pharm Biotechnol 2013;14:4-11.

7 Klug MG, Soonpaa MH, Koh GY, Field LJ: Genetically selected cardiomyocytes from differentiating embronic stem cells form stable intracardiac grafts. J Clin Invest 1996;98:216-224.

-8 Didie M, Christalla P, Rubart M, Muppala V, Döker S, Unsold B, El-Armouche A, Rau T, Eschenhagen T, Schwoerer AP, Ehmke H, Schumacher U, Fuchs S, Lange C, Becker A, Tao W, Scherschel JA, Soonpaa MH, Yang T, Lin Q, Zenke M, Han DW, Scholer HR, Rudolph C, Steinemann D, Schlegelberger B, Kattman S, Witty A, Keller G, Field LJ, Zimmermann WH: Parthenogenetic stem cells for tissue-engineered heart repair. J Clin Invest 2013;123:1285-1298.

-9 Vliegen HW, van der Laarse A, Cornelisse CJ, Eulderink F: Myocardial changes in pressure overload-induced left ventricular hypertrophy. A study on tissue composition, polyploidization and multinucleation. Eur Heart J 1991;12:488-494.

-10 Adler CP, Ringlage WP, Bohm N: DNA content and cell number in heart and liver of children. Comparable biochemical, cytophotometric and histological investigations. Pathol Res Pract 1981;172:25-41.

-11 Stiehl DP, Wirthner R, Köditz J, Spielmann P, Camenisch G, Wenger RH: Increased prolyl 4-hydroxylase domain proteins compensate for decreased oxygen levels. Evidence for an autoregulatory oxygen-sensing system. J Biol Chem 2006;281:23482-23491.

$\checkmark 12$ Klocke FJ, Kaiser GA, Ross J Jr, Braunwald E: Mechanism of increase of myocardial oxygen uptake produced by catecholamines. Am J Physiol 1965;209:913-918.

13 Suga H: Ventricular energetics. Physiol Rev 1990;70:247-277.

14 Ohgoshi Y, Goto Y, Futaki S, Yaku H, Suga H: Sensitivities of cardiac $\mathrm{O}_{2}$ consumption and contractility to catecholamines in dogs. Am J Physiol 1991;261:H196-205.

15 Tiburcy M, Didie M, Boy O, Christalla P, Doker S, Naito H, Karikkineth BC, El-Armouche A, Grimm M, Nose M, Eschenhagen T, Zieseniss A, Katschinski DM, Hamdani N, Linke WA, Yin X, Mayr M, Zimmermann WH: Terminal differentiation, advanced organotypic maturation, and modeling of hypertrophic growth in engineered heart tissue. Circ Res 2011;109:1105-1114.

-16 Cavadas MA, Nguyen LK, Cheong A: Hypoxia-inducible factor (hif) network: Insights from mathematical models. Cell Commun Signal 2013;11:42 doi: 10.1186/1478-811X-11-42.

17 Jewell UR, Kvietikova I, Scheid A, Bauer C, Wenger RH, Gassmann M: Induction of HIF-1 $\alpha$ in response to hypoxia is instantaneous. FASEB J 2001;15:1312-1314.

18 Hirsilä M, Koivunen P, Gunzler V, Kivirikko KI, Myllyharju J: Characterization of the human prolyl 4-hydroxylases that modify the hypoxia-inducible factor. J Biol Chem 2003;278:30772-30780.

19 Appelhoff RJ, Tian YM, Raval RR, Turley H, Harris AL, Pugh CW, Ratcliffe PJ, Gleadle JM: Differential function of the prolyl hydroxylases phd1, phd2, and phd3 in the regulation of hypoxia-inducible factor. J Biol Chem 2004;279:38458-38465.

20 Ginouves A, Ilc K, Macias N, Pouyssegur J, Berra E: Phds overactivation during chronic hypoxia "desensitizes" hif $\alpha$ and protects cells from necrosis. Proc Natl Acad Sci 2008;105:4745-4750.

21 Metzen E, Zhou J, Jelkmann W, Fandrey J, Brune B: Nitric oxide impairs normoxic degradation of hif-1a by inhibition of prolyl hydroxylases. Mol Biol Cell 2003;14:3470-3481.

22 Niecknig H, Tug S, Reyes BD, Kirsch M, Fandrey J, Berchner-Pfannschmidt U: Role of reactive oxygen species in the regulation of HIF-1 by prolyl hydroxylase 2 under mild hypoxia. Free Radic Res 2012;46:705-717.

-23 Clark LC Jr, Wolf R, Granger D, Taylor Z: Continuous recording of blood oxygen tensions by polarography. J Appl Physiol 1953;6:189-193. 